followed at Skåne University Hospital, and living in a defined area of southern Sweden were assessed in a cross-sectional study. USpA patients had to report back pain $\geq 3$ months before age 45 , by telephone screening, to be eligible. To enable classification, included patients underwent clinical assessments, a classification questionnaire, blood testing (including HLA-B27), and scoring of plain X-rays and MRI scans of the sacroiliac joints by an experienced radiologist.

Results: Out of 233 patients with clinical AS or axial USpA, $198(85 \%)$ fulfilled either mNY or ASAS axSpA classification criteria, while $35(15 \%)$ met neither criteria set. Among 118 patients with a clinical AS diagnosis, 103 fulfilled ASAS axSpA criteria and $84 \mathrm{mNY}$ criteria (positive predictive value [PPV] of clinical AS diagnosis for fulfilling mNY criteria was $71 \%$ and for ASAS r-axSpA 69\%). For 115 patients with a clinical USpA diagnosis, 89 fulfilled ASAS axSpA criteria, while a higher number was classified as AS ( $n=48)$ than $n r-a x S p A \quad(n=36 ;$ PPV of clinical USpA diagnosis for fulfilling nr-axSpA criteria was 31\%) (Figure).

Comparing characteristics between patients classified as radiographic axSpA (AS [mNY] and/or ASAS r-axSpA) vs. ASAS nr-axSpA, few differences were observed; the former were older, more often men, had longer disease duration and worse spinal mobility (Table).

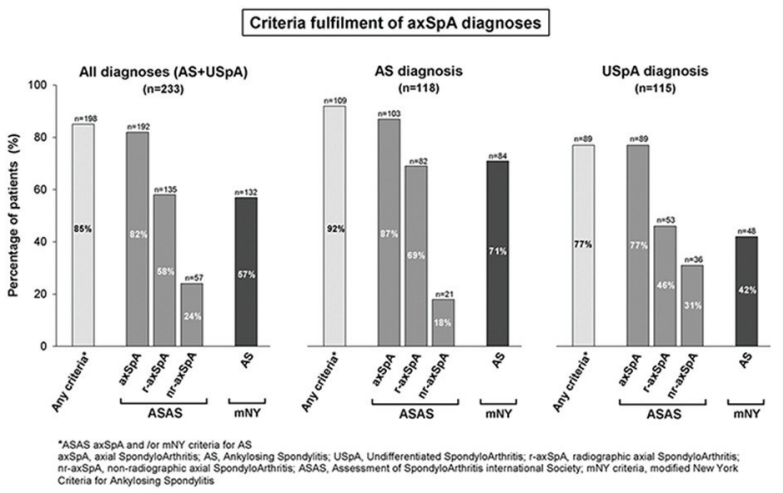

Table. Clinical characteristics and outcome measures

\begin{tabular}{|c|c|c|c|c|}
\hline & 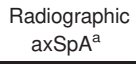 & $\begin{array}{c}\mathrm{nr}- \\
\mathrm{axSpA}\end{array}$ & $\begin{array}{l}\text { Radiographic SpA vs. nr- } \\
\qquad \operatorname{axSpA}\end{array}$ & $\begin{array}{l}\text { No } \\
\text { axSpA }\end{array}$ \\
\hline & $\mathrm{n}=141$ & $\mathrm{n}=57$ & $p$-value* & $\mathrm{n}=35$ \\
\hline Age, years & $54(14)$ & $45(12)$ & $\leq 0.001$ & $49(12)$ \\
\hline Male sex, $\mathrm{n}(\%)$ & $88(62)$ & $18(32)$ & $\leq 0.001$ & $10(29)$ \\
\hline $\begin{array}{l}\text { Symptom duration, } \\
\text { years }\end{array}$ & $29(14)$ & $19(11)$ & $\leq 0.001$ & $20(13)^{\dagger}$ \\
\hline $\begin{array}{l}\text { HLA-B27 positive, } n \\
(\%)\end{array}$ & $115(84)$ & $48(84)$ & 0.83 & $4(11)^{\dagger \S}$ \\
\hline ASDAS-CRP & $1.9(1.0)$ & $\begin{array}{c}1.9 \\
(0.9)\end{array}$ & 0.94 & $2.0(1.0)$ \\
\hline BASDAI & $3.1(2.3)$ & $\begin{array}{c}3.2 \\
(2.1)\end{array}$ & 0.77 & $3.9(2.4)$ \\
\hline BASFI & $2.3(2.4)$ & $\begin{array}{c}2.1 \\
(2.1)\end{array}$ & 0.51 & $2.8(2.3)$ \\
\hline BASMI & $3.4(1.8)$ & $\begin{array}{c}2.3 \\
(1.1)\end{array}$ & $\leq 0.001$ & $\begin{array}{c}2.7(1.0) \\
+\end{array}$ \\
\hline
\end{tabular}

Mean (SD) unless indicated. Missing data 0-14\%

*'Statistical comparisons by Student's t-test or Chi-Square test

${ }^{a}$ ASAS r-axSpA and mNY together.

statistically significant difference $(\mathrm{p}<0.05)$ radiographic axSpA vs. no axSpA and ${ }^{\S} \mathrm{nr}-\mathrm{axSpA}$ vs. no axSpA.

Conclusion: The overall concordance between clinical diagnoses and fulfilment of axSpA classification criteria was good, with $>4 / 5$ meeting any criteria. For disease subtypes, however, the agreement was substantially weaker, and a large group of patients with USpA in this established cohort fulfilled the mNY criteria for AS. The results indicate that in studies aiming to compare radiographic and non-radiographic axSpA, classification according to defined classification criteria is important.

Acknowledgement: JKW and EM contributed equally

Disclosure of Interests: Elisabet Lindqvist: None declared, Tor Olofsson: None declared, Anna Jöud: None declared, Mats Geijer Consultant for: Consultant for AbbVie, Novartis, and Pfizer., Johan $\mathrm{K}$ Wallman Consultant for: Consultant for AbbVie, Celgene, Eli Lilly, Novartis, and UCB Pharma. Elisabeth Mogard: None declared

DOI: 10.1136/annrheumdis-2019-eular.4010

\section{SAT0337 MORE THAN 30\% PATIENTS WITH EARLY AXIAL SPONDYLOARTHRITIS PRESENT WITH PERIPHERAL ARTHRITIS: INCIDENCE AND FACTORS ASSOCIATED DURING 5 YEARS OF FOLLOW-UP OF THE DESIR COHORT}

Clementina López-Medina ${ }^{1}$, Adeline Ruyssen-Witrand ${ }^{2}$, Maxime Dougados ${ }^{1}$ Anna Moltó ${ }^{1} .{ }^{1}$ Cochin Hospital, Rheumatology, Paris, France; ${ }^{2} \mathrm{CHU}$ Purpan, Rhumatologie et Immunologie Clinique, Toulouse, France

Background: Peripheral arthritis is the most frequent peripheral manifestation in Spondyloarthritis $(\mathrm{SpA})$. However, there is a lack of knowledge about its prevalence and incidence over time in recent axial $\mathrm{SpA}(\operatorname{axSpA})$. Objectives: a) To describe the prevalence and incidence of peripheral arthritis during 5 years of follow-up on the DESIR cohort; b) to describe the time of onset regarding axial symptoms; c) to evaluate factors associated with their appearance; d) to evaluate the impact of this symptom on treatment, Patient Reported Outcomes (PROs) and sick leave during 5 years of follow-up.

Methods: Data from the early axSpA patients from the DESIR cohort (first 5 years of follow-up) were analysed. The prevalence and the incidence of peripheral arthritis at each study visit were calculated. A Kaplan-Meier curve was performed to evaluate the time of onset of this manifestation regarding the axial symptoms onset. Univariate and multivariate logistic regressions were performed to evaluate baseline factors associated to the development of the arthritis. We compared the use of drugs between patients with and without arthritis by Chi-square test, and finally we evaluate the impact of this symptom on PROs (BASDAI, BASFI and SF36questionnaire) and on days of sick leave after 5 years of follow-up through the use of a mixed model with random effects (patients).

Results: Out of the 708 patients included in the analysis, 255 (36.0\%) showed at least one episode of arthritis (151 before the inclusion visit, and 104 during the follow-up), with a time-person rate of 3.7 cases per 100 person-year. Regarding axial symptoms, $20.4 \%, 13.70 \%$ and $65.9 \%$ patients suffered the first episode of arthritis before, concomitantly and after axial symptoms onset, respectively. Multivariate analysis showed that baseline factors associated to the development of arthritis are age $>33$ years (OR 1.60, 95\% $\mathrm{Cl} 1.12-2.27$ ), non-smokers (OR 1.58, 95\% Cl 1.102.27), HLAB27 negative (OR 1.47, 95\% $\mathrm{Cl} 1.04-2.08$ ), CRP $>6 \mathrm{mg} / \mathrm{dl}$ (OR $1.99,95 \% \mathrm{Cl} 1.35-2.92$ ), no history of uveitis (OR 2.03, $95 \% \mathrm{Cl} 1.07-3.84$ ), dactylitis (OR $8.50,95 \% \mathrm{Cl} 4.96-14.60$ ) and enthesitis (OR 2.00, 95\%C 1.41-2.84). Concerning the use of drugs, patients with arthritis showed a significant greater use of TNF blockers $(49.4 \%$ vs. $29.1 \%, p<0.001)$, csDMARDs $(40.4 \%$ vs. $13.9 \%, \mathrm{p}<0.001)$, oral corticosteroids $(37.6 \%$ vs $22.1 \%, p<0.001)$ and $\geq 1$ intraarticular corticosteroids $(31.0 \%$ vs. $6.8 \%$ $\mathrm{p}<0.001$ ), in comparison with patients without history of arthritis. We did not found differences concerning NSAIDs, intramuscular and intravenous corticosteroids. Finally, the mixed model showed that, after 5 years of follow-up, patients with arthritis had higher levels on BASDAI $(40.5 \pm 22.6$ vs. $34.3 \pm 20.7, \quad p<0.001)$ and BASFI $(27.9 \pm 23.2$ vs. 22.5 $\pm 21.0, p=0.001)$, poorer quality of life (SF36-mental component $42.7 \pm 11.7$ vs. $44.0 \pm 11.0$, $\mathrm{p}=0.003$; SF-36 physical component $40.9 \pm 9.7$ vs. $43.1 \pm 0.2, p<0.001)$ and higher number of days of sick leave (18.0 \pm 57.5 vs. $12.8 \pm 47.2, p=0.024)$. Conclusion: In recent axSpA, $36 \%$ of patients reported peripheral arthritis at any time of the disease, and this appeared more frequently after axial symptoms onset. This symptom is more prevalent among patients with HLAB27 negative, non-smokers, with high CRP and with other peripheral manifestations. Arthritis were associated with a greater use of bDMARDs, csDMARDs and corticosteroids, and had an impact on function, quality of life and days of sick leave.

Disclosure of Interests: Clementina López-Medina: None declared, Adeline Ruyssen-Witrand: None declared, maxime dougados Grant/research support from: Eli Lilly and Company, Pfizer, AbbVie, and UCB Pharma, Consultant for: Eli Lilly and Company, Pfizer, AbbVie, and UCB Pharma, Anna Moltó: None declared

DOI: 10.1136/annrheumdis-2019-eular.3480

\section{SAT0338 DELAYED DIAGNOSIS OF ANKYLOSING SPONDYLITIS: RESULTS FROM A SURVEY OF 1690 US PHYSICIANS FROM 10 SPECIALTIES}

Marina Magrey ${ }^{1}$, Esther $\mathrm{Yi}^{2,3}$, Daniel Wolin ${ }^{4}$, Mark Price ${ }^{4}$, Costel Chirila ${ }^{4}$, Eric Davenport ${ }^{4}$, Yujin Park ${ }^{5} .{ }^{1}$ Case Western Reserve University, Cleveland, United States of America; ${ }^{2}$ The University of Texas at Austin, Austin, United States of America; ${ }^{3}$ Baylor Scott and White Health, Temple, United States of America; ${ }^{4}$ RTI Health Solutions, Research Triangle Park, United States of America;

${ }^{5}$ Novartis Pharmaceuticals Corporation, Hanover, United States of America

Background: There is a significant delay in the diagnosis of ankylosing spondylitis (AS) in the United States. Several studies have estimated that 
the time between symptom onset and physician diagnosis is 5-7 years. Diagnosis delay is attributed to nonspecific presentation of chronic back pain, requiring clinical experience to recognize early AS.

Objectives: To identify obstacles to early diagnosis of AS by assessing the knowledge of nonrheumatology health care providers (HCPs) on inflammatory back pain (IBP) and possible barriers to referral to a rheumatologist.

Methods: Survey content was first conceptualized based on concept elicitation interviews with HCPs, and questionnaires were developed by the study investigators to identify clinical characteristics, symptom presentation, and diagnostic measures that lead an HCP to suspect IBP and their perspectives on the referral process. The survey was then cognitively tested with HCPs from 10 specialties (family medicine, internal medicine, dermatology, gastroenterology, ophthalmology, orthopedics, chiropractic, pain management, physical therapy, and physiatry), revised, and finalized. HCPs from these 10 specialties were invited to participate in the crosssectional web-based survey hosted by Survey Sampling International between June 27 and July 20, 2018. HCPs who were currently licensed, actively practicing in the US, and had referred a patient with suspected IBP (except ophthalmology) or referred a patient with uveitis/iritis (ophthalmology only) within the past 12 months were eligible to participate. Descriptive statistics were used to analyze the data.

Results: Of 2395 HCPs screened, 1690 were eligible and included in our study. Overall, HCPs saw a median of 100 patients with chronic back pain within the past 12 months of the survey. Regarding criteria leading to suspicion of IBP, $61 \%$ of HCPs indicated morning stiffness > 30 minutes, $29 \%$ sleep disturbance due to back pain, $28 \%$ pain that improves with activity, and $16 \%$ alternating buttock pain. Among HCPs who would order diagnostic blood work, $\approx 90 \%$ selected C-reactive protein, erythrocyte sedimentation rate, antinuclear antibody (ANA), and rheumatoid factor (RF), while $76 \%$ selected HLA-B27 (Figure 1).. Most HCPs suspected underlying conditions of rheumatoid arthritis (RA; 94\%), AS $(90 \%)$, and psoriatic arthritis $(81 \%)$ as related to IBP. Almost $40 \%$ of HCPs would treat patients with suspected IBP themselves; of these, $\approx$ $80 \%$ would recommend nonsteroidal anti-inflammatory drugs and physical therapy (Figure 2).. Regarding referrals, 57\% of HCPs would refer patients with suspected IBP to another physician, but only $13 \%$ would refer immediately; $49 \%$ would perform further evaluations, $24 \%$ would wait until initial treatment response, $11 \%$ would monitor patient for some time, and $3 \%$ would consult with another physician before referring. Upon referral, $90 \%$ of HCPs estimated a wait time of up to 2 months for their patient to see another specialist. Of $1670 \mathrm{HCPS}$ queried, $80 \%$ indicated that the specialist's expertise in treating autoimmune disease is the most important factor influencing their referral.

Conclusion: Most HCPs did not recognize IBP criteria in patients with chronic back pain. As most considered RA to be the underlying condition, ANA and RF were ordered as diagnostic workup. Many HCPs opted to treat and monitor patients with suspected IBP before referral, and most reported a wait time of up to 2 months for their patients to see a specialist.

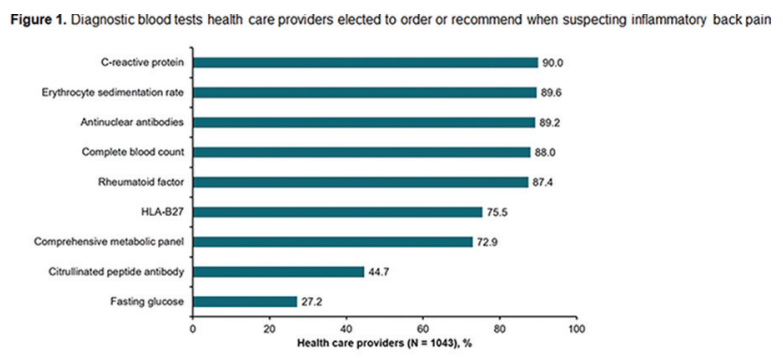

Figure 2. Treatment recommendations by health care providers who opted to treat patients with suspected

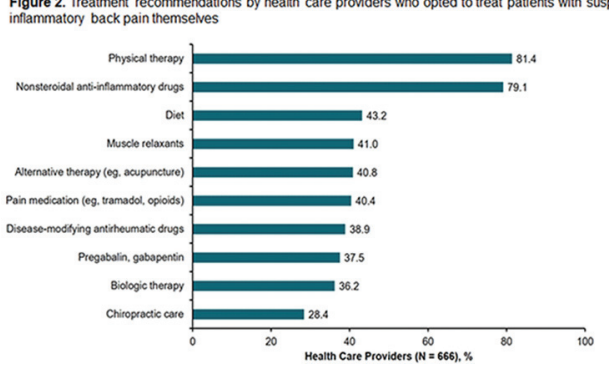

Acknowledgement: This study was sponsored by Novartis Pharmaceuticals Corporation, East Hanover, NJ.

Disclosure of Interests: Marina Magrey Grant/research support from: $M$. Magrey received research funding from AbbVie and UCB for clinical trials, served as a consultant for Novartis, and was a member of advisory boards for Eli Lilly, Novartis, and UCB, Consultant for: M. Magrey received research funding from AbbVie and UCB for clinical trials, served as a consultant for Novartis, and was a member of advisory boards for Eli Lilly, Novartis, and UCB, Esther Yi Consultant for: E. Yi is a postdoctoral fellow at the University of Texas at Austin and Baylor Scott and White Health, providing services to Novartis Pharmaceuticals Corporation., Daniel Wolin Employee of: D. Wolin is an employee of RTI Health Solutions., Mark Price Employee of: M. Price is an employee of RTI Health Solutions., Costel Chirila Employee of: C. Chirila is an employee of RTI Health Solutions., Eric Davenport Employee of: E. Davenport is an employee of RTI Health Solutions., Yujin Park Employee of: Y. Park is an employee of Novartis.

DOI: 10.1136/annrheumdis-2019-eular.501

\section{SAT0339 WHAT IS THE IMPACT OF IMAGING ON DIAGNOSTIC ASCERTAINMENT OF PATIENTS PRESENTING WITH UNDIAGNOSED BACK PAIN AND WHAT IS THE IMPACT OF CENTRAL EVALUATION? DATA FROM THE SCREENING IN AXIAL SPONDYLOARTHRITIS IN PSORIASIS, IRITIS, AND COLITIS (SASPIC) COHORT}

Walter P. Maksymowych ${ }^{1,2}$, Raj Carmona ${ }^{3}$, James Yeung ${ }^{4}$, Jon Chan ${ }^{5}$, Liam Martin $^{6}$, Sibel Aydin ${ }^{7}$, Dianne Mosher ${ }^{6}$, Ariel Masetto ${ }^{8}$, Stephanie Keeling ${ }^{1}$, Olga Ziouzina ${ }^{6}$, Sherry Rohekar ${ }^{9}$, Joel Paschke ${ }^{2}$, Amanda Carapellucci ${ }^{2}$, Robert G. Lambert ${ }^{1} .{ }^{1}$ University of Alberta, Edmonton, Canada; ${ }^{2}$ CaRE Arthritis, Edmonton, Canada; ${ }^{3}$ McMaster University, Hamilton, Canada; ${ }^{4}$ James Yeung Rheumatology, Vancouver, Canada; ${ }^{5}$ Artus Health Center, Vancouver, Canada; ${ }^{6}$ University of Calgary, Calgary, Canada; ${ }^{7}$ University of Ottawa, Ottawa, Canada; ${ }^{8}$ University of Sherbrooke, Sherbrooke, Canada; ${ }^{9}$ Lawson Health Research Institute, London, Canada

Background: Although MRI of the sacroiliac joints (SIJ) is the most sensitive imaging modality for early diagnosis of axial spondyloarthritis $(\operatorname{axSpA})$ it is costly and not readily available. Therefore, clinicians still rely primarily on radiography. The relative degree to which radiography and MRI changes diagnostic ascertainment of axSpA in patients presenting with undiagnosed back pain has not been formally studied.

Objectives: We aimed to assess the relative impact of radiography and MRI evaluation on diagnostic ascertainment of axial SpA in patients presenting with undiagnosed back pain to rheumatologists, and the impact of central evaluation.

Methods: The multicenter Screening for Axial Spondyloarthritis in Psoriasis, Iritis, and Colitis (SASPIC) Study is aimed at early detection of axial SpA. Consecutive patients $\leq 45$ years of age with $\geq 3$ months undiagnosed back pain with any one of psoriasis, acute anterior uveitis (AAU), or colitis undergo routine clinical evaluation by a rheumatologist for axial $\mathrm{SpA}$ and MRI evaluation is ordered per rheumatologist decision. The rheumatologist determines the presence or absence of axial SpA at 3 consecutive stages: 1. After the clinical evaluation; 2. After the results of labs (B27, CRP) and radiography; 3. After the results of MRI evaluation. The eCRF, radiographs, and MRI scans were also assessed centrally. Results: The SASPIC cohort comprises 246 patients $(52.4 \%$ male, mean age 34.5 years, mean symptom duration 7.3 years, mean back pain duration 7.1 years, B27+ 36.2\%) referred with AAU (29.7\%), psoriasis

\begin{tabular}{|c|c|c|c|c|c|}
\hline $\begin{array}{l}\text { Stage of } \\
\text { global } \\
\text { assessment }\end{array}$ & Data source & $\begin{array}{c}\text { axSpA } \\
\text { YES }\end{array}$ & $\begin{array}{c}\text { axSpA YES } \\
\text { with } \\
\text { confidence } \\
>7 \\
\end{array}$ & $\begin{array}{c}\text { NOT } \\
\text { axSpA }\end{array}$ & $\begin{array}{c}\text { axSpA NO } \\
\text { with } \\
\text { confidence } \\
<-4\end{array}$ \\
\hline 1. $N=246$ & Clinical & $\begin{array}{c}169 \\
(68.7 \%)\end{array}$ & $50(20.3 \%)$ & $\begin{array}{c}77 \\
(31.3 \%)\end{array}$ & $40(16.3 \%)$ \\
\hline 2. $N=246$ & $\begin{array}{l}\text { Clinical plus } \\
\text { radiography }\end{array}$ & $\begin{array}{c}141 \\
(57.3 \%)\end{array}$ & $66(26.8 \%)$ & $\begin{array}{c}105 \\
(42.7 \%)\end{array}$ & $78(31.7 \%)$ \\
\hline \multicolumn{6}{|c|}{ Patients who had MRI } \\
\hline 1. $N=149$ & Clinical & $\begin{array}{c}107 \\
(71.8 \%)\end{array}$ & $23(15.4 \%)$ & $\begin{array}{c}42 \\
(28.2 \%)\end{array}$ & $19(12.8 \%)$ \\
\hline 2. $N=149$ & $\begin{array}{l}\text { Clinical plus } \\
\text { radiography }\end{array}$ & $\begin{array}{c}94 \\
(63.1 \%)\end{array}$ & $30(20.1 \%)$ & $\begin{array}{c}55 \\
(36.9 \%)\end{array}$ & $38(25.5 \%)$ \\
\hline 3. $N=149$ & $\begin{array}{c}\text { Clinical plus } \\
\text { radiography } \\
\text { plus MRI }\end{array}$ & $\begin{array}{c}70 \\
(\mathbf{4 7 . 0 \% )}\end{array}$ & $44(29.5 \%)$ & $\begin{array}{c}79 \\
(53.0 \%)\end{array}$ & $70(47.0 \%)$ \\
\hline
\end{tabular}

